\title{
Stereological Survey of the Effect of Vitamin C on Neonatal Rat Kidney Tissue Treated With Acrylamide
}

\author{
Hengameh Dortaj ${ }^{1}$, Morteza Anvari ${ }^{2}$, Maryam Yadegari ${ }^{3}$, \\ Mohammad Hosseini Sharifabad $^{\mathbf{1}}$, Abolghasem Abbasi Sarcheshmeh ${ }^{\mathbf{1}}$
}

1. Dept. of Anatomy and Cell Biology, Shahid Sadoughi University of Medical Sciences and Health Services, Yazd, Iran 2. Reserch and Clinical Centre for infertility, Shahid Sadoughi University of Medical Sciences and Health Services, Yazd, Iran 3. Dept of Anatomy and Cell Biology, Shahid Sadoughi University of Medical Sciences and Health Services, Yazd, Iran

\section{KEYWORDS}

Acrylamide

Ascorbic Acid

Kidney Injury

Rats

Stereology

Article Info

Received 2018/05/21;

Accepted 2018/06/26;

Published Online 2018

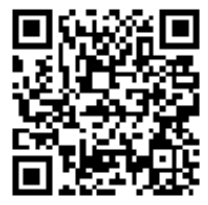

\section{ABSTRACT}

Background and Objectives: Acrylamide (ACR) is a known carcinogenic chemical agent found in some foods at considerably high concentration. The aim of this study was to investigate the protective effects of vitamin $\mathrm{C}$ as an antioxidant on kidney tissue in rats treated with ACR.

Methods: Twenty female Wistar rats (200-220 grams) were divided into 4 groups $(\mathrm{n}=5)$ of control group, ACR group, vitamin $\mathrm{C}$ group and $\mathrm{ACR}+$ vitamin $\mathrm{C}$ group. Pregnant rats were orally administered $10 \mathrm{mg} / \mathrm{kg}$ ACR and/or $200 \mathrm{mg} / \mathrm{kg}$ vitamin C. Six infants at day 21 after birth were randomly selected and weighted

with hematoxylin and eosine and periodic acid staining and studied using stereological methods. Data was analyzed using one way ANOVA and LSD test and means difference were considered significant at $\mathrm{P}<0.05$.

Results: Mean body weight, kidney weight, kidney volume, the volume of cortex and medulla, number of glomeruli and thickness of medulla significantly decreased in ACR group compared to the controls $(\mathrm{P}<0.001)$. The thickness of cortex also decreased in ACR group compared to the control group $(\mathrm{P}<0.05)$. In vitamin $\mathrm{C}$ group, body weight, kidney volume and number of glomeruli increased compared to the control group $(\mathrm{P}<0.001)$. In vitamin $\mathrm{C}$ group, increased kidney weight, thickness of medulla, volume of cortex and glomeruli were observed compared to the control $(\mathrm{P}<0.05)$. In $\mathrm{ACR}+$ vitamin $\mathrm{C}$ group, this reduction was less significant compared to the ACR group.

Conclusion: Vitamin $\mathrm{C}$ as an antioxidant can protect the kidneys from ACR induced tissue damage.

Corresponding Information: Dr. Maryam Yadegari, Ph.D., Dept of Anatomy and Cell Biology, Shahid Sadoughi University of Medical Sciences and Health Services, Yazd, Iran, E-mail: yadegari_m@yahoo.com

Copyright ( $\odot$ 2018. This is an open-access article distributed under the terms of the Creative Commons Attribution-noncommercial 4.0 International License which permits copy and redistribute the material just in noncommercial usages, provided the original work is properly cited.

\section{Introduction}

In recent years, harmful effect of acrylamide (ACR) in foods has attracted much attention (1). ACR (C3H5NO) is a white, odorless, crystalline solid at room temperature (2). It has small hydrophilic vinyl monomer molecules with many chemical and industrial applications (3). The International Agency for Research on Cancer classified ACR as a probable human carcinogen on the basis of its carcinogenicity in rodents (4). Before 2002, exposure to ACR had occurred mainly by exposure in workers, furthermore by smoking and expenditure of water and consumption of cosmetic products $(5,6)$. However in 2002, scientists reported its presence in carbohydrate-rich foods produced at high temperatures (higher than $200^{\circ} \mathrm{C}$ ), especially when asparagines react with sugar $(4,7)$. ACR can undergo oxidative biotransformation by cytochrome P450 (8). The eventuate metabolite is an epoxide formation like glycidamide that is more passive for proteins and DNA than the original compound ACR (9). ACR also crosses placenta to 
developing fetus significantly, leading to direct prenatal and postnatal anomalies (10). ACR is existent in foods at extremely higher condensation up to other popular food carcinogens (11). ACR quickly metabolizes in body and its metabolites are mostly excreted through the urine (12). The antioxidant and free radical scavenger ascorbic acid (vitamin $\mathrm{C}$ ) has a protective effect against drug-induced nephrotoxicity in animals $(13,14)$. In humans, nephrogenesis happens within embryonic period and stops after geniture. However, in rats it happens within the latter term of pregnancy and follow out since geniture (15). Interference within the third trimester embryonic development has been demonstrated to modify nephron development (16). Kidney volume and the thickness of cortex is clinically important because kidney size gives insight into kidney function (17). The volume of biological structures can be obtained by the cavalirie principle. Methods of stereological counting are used for quantitative analysis of three-dimensional structures and can analyze cell number and size at microscopic level (18). Number estimation of kidney structures may have great impact to study development, growth and transformation of the kidney (19). The present study was conducted to evaluate the histopathological effect of ACR treatment on development of kidney in rat and also to determine the effect of vitamin $\mathrm{C}$ as an antioxidant.

\section{Material and Methods}

\section{Animals and Treatment}

We used 20 female and 10 male Wistar rats (50-60 days old, 200-220 grams). The male rats were used for fertilization of female ones. Gestation was authenticated by perception of vaginal plaque. Female pregnant rats were randomly divided into 4 groups as control group, ACR group, vitamin $\mathrm{C}$ group and $\mathrm{ACR}+$ vitamin $\mathrm{C}$ group. Rats in the control group were preserved under normal condition of diet and water. In the experimental group, we used $10 \mathrm{mg} / \mathrm{kg} / \mathrm{day}$ ACR and $200 \mathrm{mg} / \mathrm{kg} /$ day vitamin $\mathrm{C}$ orally from 7 th day of gestation and continued up to 21 days after delivery.

\section{Surgical Procedure}

At 21th day, 5 neonates were selected from each group and their weight measured. The rats were then anesthetized under ether and retrograde perfusion trough the left ventricle of heart. The solution for perfusion contained $4 \%$ formaldehyde and $1 \%$ glutaraldehyde in 0.1 phosphate buffer for 5 minutes. Right kidneys were released from their fatty covering connecting tissue and gently removed. The kidneys were then irrigated with physiologic serum. The weight of the kidneys was measured using analytic scale. Then, the collected kidneys were kept in $10 \%$ buffered formaldehyde solution for 10 days (20). All procedures used in this study were approved by the Ethical Committee of Shahid Sadoughi University of Medical Sciences Yazd - Iran.

\section{Volume of cortex, medulla and glomeruli}

Following routine histological processing, paraffin kidney blocks were collected and sectioned in identity with systematic random sampling. Depending on the size of kidneys, 11-13 $5 \mu$-thick samples were obtained, and every tenth section selected from all kidneys. All samples were stained with hematoxylin and eosine (H\&E) method. A calibrated micrometer eyepiece of microscope was used to measure the thickness of cortex and medulla. The whole kidney was viewed on a light microscope at a magnification of $10 x$ with the image projected on a computer monitor. Volume calculations were performed using Cavalieri's principle. A point grid with $100 \mu$ distance between two points was overlaid on the images. Hitting points on the cortex and medulla were counted and then the volume of each component was calculated using the following formula:

$$
\mathrm{V}=\mathrm{t} \times \mathrm{a}(\mathrm{p}) \times \Sigma \mathrm{P} / \mathrm{M}^{2}
$$

Where $\mathrm{V}$ refers to volume component of interest, $\mathrm{t}$ is the section thickness, $\mathrm{a}(\mathrm{p})$ is the area of one point $(1000 \mu), \Sigma \mathrm{P}$ is the total number of point counted in the component of interest, and $\mathrm{M}$ is the linear magnification (21).

\section{Numerical density of glomerul and total number of glomerul}

Selection of the physical dissector pairs was performed as described by Stereo. Based on the findings obtained from a pilot study, the first 
chosen section and its adjacent section, called a dissector pair, were separated by a distance of $30 \mu$ as a rule of physical dissector. According to this rule, the distance between the sections pairs must be about $30-40 \%$ of the average projected height of the object of interest (in this study glomeruli) to be estimated. In this way, approximately 15- 20 section pairs were obtained and evaluated. Two consecutive sections were mounted on each slide. Photographs of adjacent sections were taken with a digital camera at a magnification of $400 \times$. An unbiased counting frame was placed on the reference and the look-up sections on the screen of the $\mathrm{PC}$, to perform counting according to the dissector method. The bottom and the left-hand edges of the counting frame were considered to be the forbidden (exclusion) lines together with the extension lines. Other boundaries of the frame that are the top-right edges were considered to be inclusion lines, and any particle that hit these lines or was located inside the frame was counted as a dissector particle. The size of the unbiased counting frame was adjusted to count 100-200 glomeruli from each sample. The dimension of the counting frame on the PC screen was $10 \times 10 \mathrm{~cm}$.
Glomeruli seen in the reference section but not in the look-up section were counted.

The mean numerical density of glomeruli was estimated using the following formula:

$\mathrm{NV}=\Sigma \mathrm{Q} / \mathrm{t} \times \mathrm{a}(\mathrm{p})$

Where $\Sigma \mathrm{Q}$ is the total number of glomerul counted in the reference section, $t$ is the mean section thickness $(5 \mathrm{~m})$ and $\mathrm{a}(\mathrm{p})$ is the area of the unbiased counting frame.

The total number of glomerul in a whole rat kidney was estimated by the following equation:

$\mathrm{T}_{\mathrm{n}}=\mathrm{N}_{\mathrm{V}} \times \mathrm{V}_{\mathrm{KIDNEY}}$

Where $\mathrm{N}_{\mathrm{V}}$ is the numerical density of glomerul, $\mathrm{Tn}$ is total number of glomeruli in the whole kidney calculated using the kidney volume results estimated by the Cavalieri method $(22,23)$.

\section{Statistical Analysis:}

All values expressed as mean \pm standard deviation (SD). One way ANOVA and LSD test were used to evaluate the results. Differences with $\mathrm{P}<0.05$ were considered significant.

\section{Results}

The results of body and kidney weight, cortex and medulla's thickness for each group are presented in Table 1.

Table1: Comparison between control and experimental groups regarding body weight, kidney weight, cortex and medulla thickness.

\begin{tabular}{lcccc}
\multicolumn{1}{c}{ Group } & Control & Acrylamide & Vitamin C & Acrylamide+Vitamin C \\
\hline Body Weight $(\mathbf{g r})$ & $35.75 \pm 6.021$ & $31.25 \pm 7.136^{*}$ & $38.65 \pm 5.737^{* *}$ & $34.25 \pm 7.455$ \\
\hline Kidney Weight $(\mathbf{g r})$ & $0.302 \pm 0.007$ & $0.248 \pm 0.115^{* *}$ & $0.323 \pm 0.015^{* *}$ & $0.268 \pm 0.005^{* *}$ \\
\hline Cortex Thickness $(\mathbf{m m})$ & $62.25 \pm 4.203$ & $57.5 \pm 2.082$ & $63 \pm 3.742^{* *}$ & $60.25 \pm 1.708^{*}$ \\
\hline Medulla Thicknes $(\mathbf{m m})$ & $148.5 \pm 4.203$ & $130.25 \pm 5.123$ & $154 \pm 4.6900^{* *}$ & $133.5 \pm 4.509^{* *}$ \\
\hline
\end{tabular}

The results are shown as mean \pm SEM. $\mathrm{P}<0.05$ is indicated by"*" and $\mathrm{P}<0.001$ by"***".

\section{Histopathological observations:}

Comparative histopathological analysis of tissue samples from each group was performed by light microscope studies, to evaluate the effects of ACR and vitamin $\mathrm{C}$ treatment. In control and vitamin $\mathrm{C}$ groups, glomeruli had normal structures. In ACR group, hyalinized glomeruli and degeneration was seen. Damage to the kidney tubules was observed as vacuolated cells. These changes were associated with destruction of all the renal parenchymal tissue in ACR group. In
ACR+vitamin $\mathrm{C}$ group, these changes caused by ACR did not decrease (Figures 1, 2, 3).

\section{Volume of kidney structures:}

Stereological investigation in the four groups showed that total volume of the kidneys in ACR group was significantly decreased compared to the controls $(\mathrm{P}<0.001)$. The mean volume of kidneys in vitamin $\mathrm{C}$ group was significantly higher than the control group $(\mathrm{P}<0.001)$. In $\mathrm{ACR}+$ vitamin $\mathrm{C}$ group, compared to control, mean volume of the kidneys decreased but not significant $(\mathrm{P}=0.1)$ (Figure 4). 

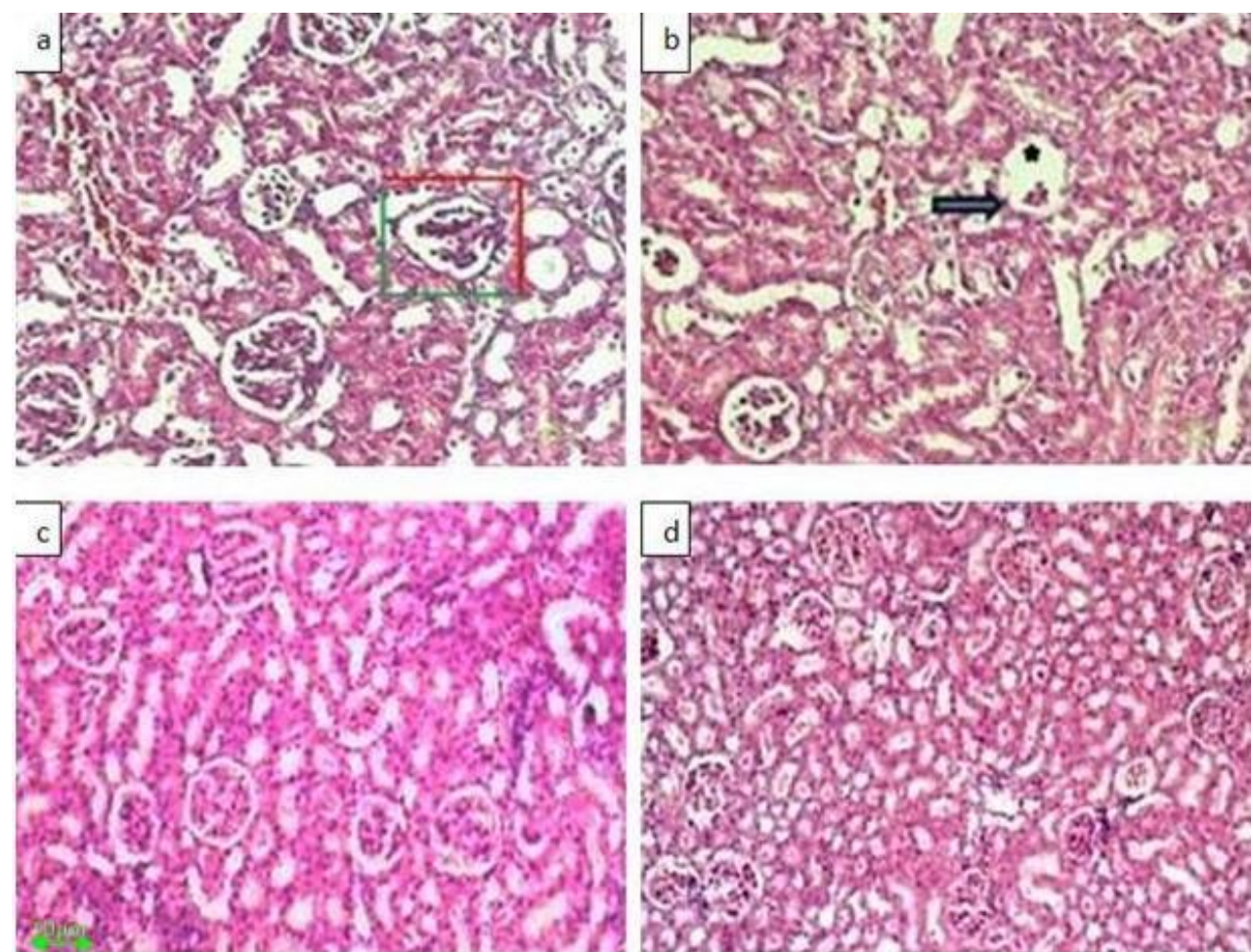

Figure1: Light photomicrograph ACR changes and estimation of the number of glomeruli using grid and physical dissector method. Forbidden sides and allowed to count (red and green) are indicated. There were no histological changes in the control group (a), but in ACR group (b) the glomeruli demonstrated fibrosis, and shrinkage resulting in crowding of hyalinised glomeruli (arrow) and widening of the Bowman's space (star). Vitamin C (c) glomeruli had normal structures. In ACR+ vitamin C, number of glomeruli increased compared to

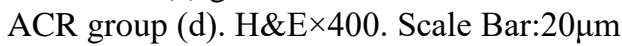
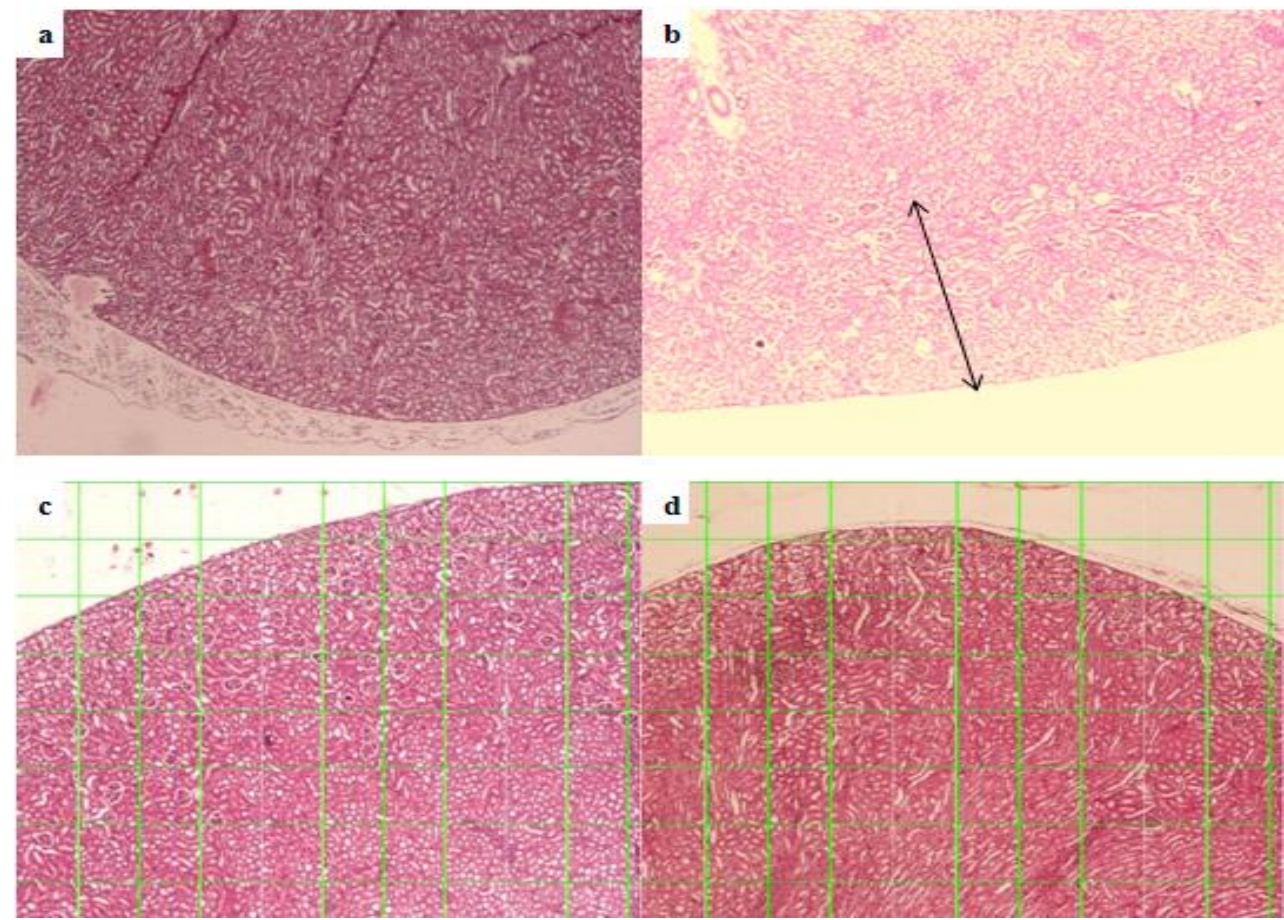

Figure2: light photomicrographs estimating volume cortex, medulla and whole kidney by grid and physical dissector method. Cortex and medullar volume in ACR group decreased and in vitamin C group increased compared to the control. In ACR+vitamin $\mathrm{C}$ group this reduction was less significant compared to ACR group. Thickness of cortex is shown by arrow. a)control ,b) ACR, c)vitamin C, d) ACR+ vitamin C. H\&E×400. Scale

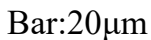


Estimated volume of cortex by stereological analysis in the four groups revealed that cortex volume in ACR and ACR+vitamin $\mathrm{C}$ group were less than the control group $(\mathrm{P}<0.001)$, while cortex volume in vitamin $\mathrm{C}$ group was significantly higher than the control $(\mathrm{P}<0.05)$. (Figure 5)

Estimated volume of medulla by stereological analysis demonstrated that mean medullar volume in ACR group was less than the control group $(\mathrm{P}<0.001)$. Medullar volume in $\mathrm{ACR}+$ vitamin $\mathrm{C}$ group was also decreased but it was $\mathrm{P}<0.05$. In vitamin $\mathrm{C}$ group, medullar volume was more than the control group but the difference was not significant $(\mathrm{P}=0.2)$. (Figure 6)

Stereological investigation for estimating the volume of glomeruli showed that mean glomeruli volume in ACR group was significantly decreased compared to the control group $(\mathrm{P}<0.001)$. It was also decreased in ACR+vitamin $\mathrm{C}$ group but not significant $(\mathrm{P}=0.4)$. In vitamin $\mathrm{C}$ group, mean glomeruli volume was more than control $(\mathrm{P}<0.05)$. (Figure 7)

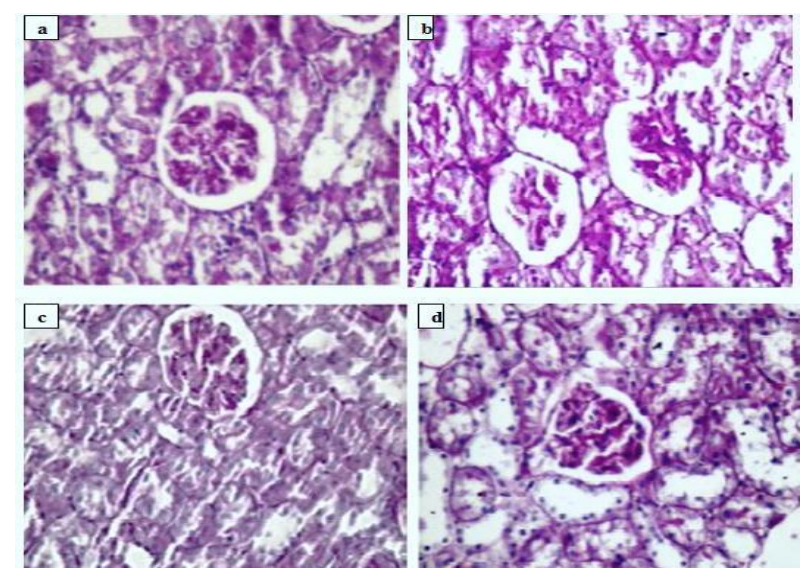

Figure3: Light photomicrograph of different groups. a) control: normal glomerulus and kidney tissue, b)ACR: tubular injury with thickened basement membrane, c) vitamin $\mathrm{C}$ : normal basement membrane and glomerulus, d)ACR+ vitamin $\mathrm{C}$ : reduces shrinkage of glomerulus after treatment. (PAS staining x400). Scale Bar: $25 \mu \mathrm{m}$.

\section{Estimated number of glomeruli;}

The number of glomeruli in ACR $(\mathrm{P}<0.001)$ and $\mathrm{ACR}+$ vitamin $\mathrm{C}(\mathrm{P}<0.05)$ groups were decreased compared to the control. Glomerular count in vitamin $\mathrm{C}$ group was significantly higher than the control group $(\mathrm{P}<0.001)$. (Figure 8)

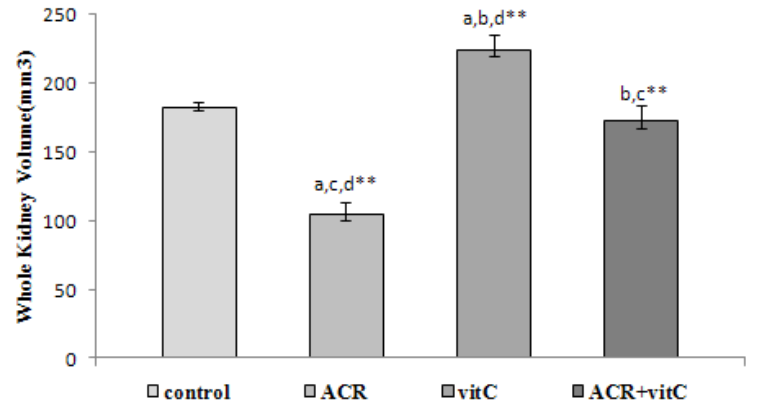

Figure4: Mean whole volume of kidneys $\left(\mathrm{mm}^{3}\right)$. Comparison between controls and the other groups (a), comparison between vitamin $\mathrm{C}$ group with other groups (b), comparison between ACR+ vitamin $\mathrm{C}$ with other groups (c) and comparison between ACR and other groups (d). $\mathrm{P}<0.05$ is indicated by"*" and $\mathrm{P}<0.001$ by"**".

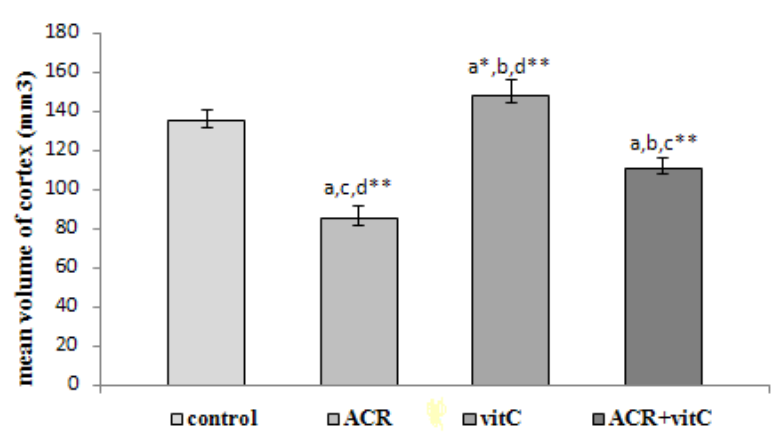

Figure5: Mean volume of cortex $\left(\mathrm{mm}^{3}\right)$. Comparison between control and other groups (a), comparison between vitamin $\mathrm{C}$ group and other groups (b), comparison between $\mathrm{ACR}+$ vitamin $\mathrm{C}$ and other groups (c) and comparison between ACR and other groups (d). $\mathrm{P}<0.05$ is indicated by "*" and $\mathrm{P}<0.001$ by"**".

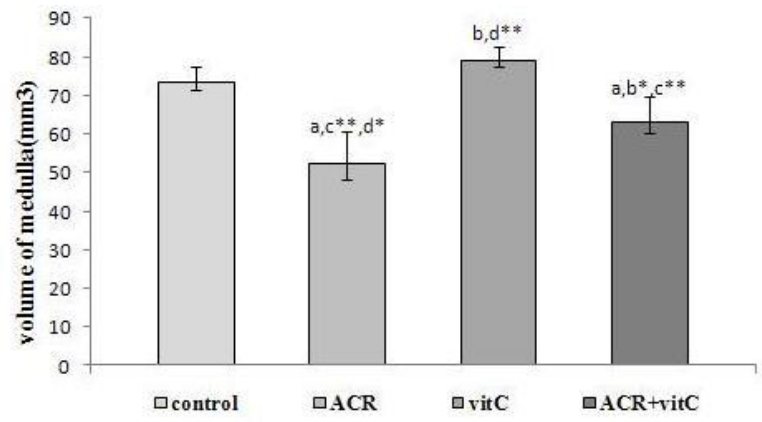

Figure6: Volume of medulla $\left(\mathrm{mm}^{3}\right)$. Comparison between control and other groups (a), comparison between vitamin $\mathrm{C}$ groups and other groups (b), comparison between $\mathrm{ACR}+$ vitamin $\mathrm{C}$ and other groups (c) and comparison between ACR and other groups (d). $\mathrm{P}<0.05$ is indicated by "*" and $\mathrm{P}<0.001$ by"**". 


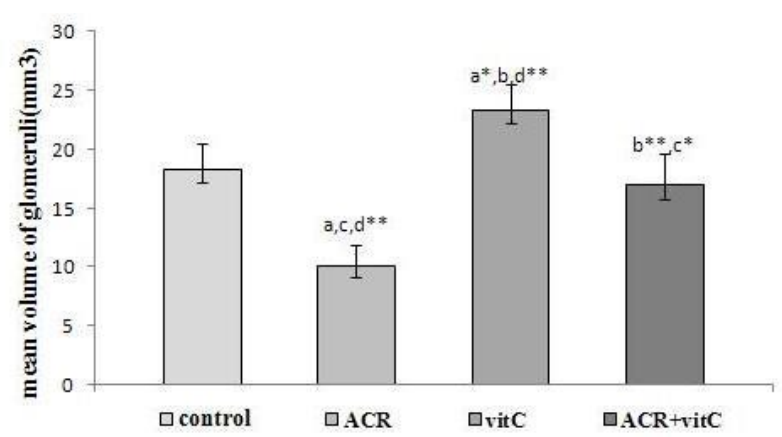

Figure7: Mean volume of glomeruli $\left(\mathrm{mm}^{3}\right)$. Comparison between control and other groups (a), comparison between vitamin $\mathrm{C}$ group and other groups (b), comparison between ACR+ vitamin C and other groups (c) and comparison between ACR and other groups (d). $\mathrm{P}<0.05$ is indicated by "*" and $\mathrm{P}<0.001$ by"**".

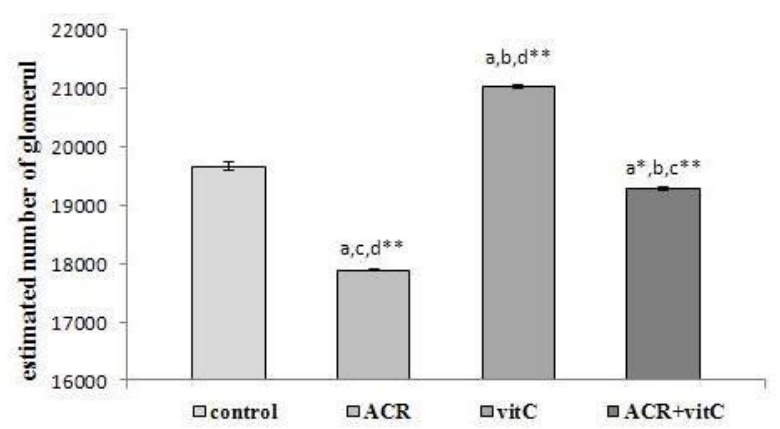

Figure8: Estimated number of glomeruli. Comparison between controls and other groups (a), comparison between vitamin $\mathrm{C}$ group and other groups (b), comparison between $\mathrm{ACR}+$ vitamin $\mathrm{C}$ and other groups (c) and comparison between ACR and other groups (d). $\mathrm{P}<0.05$ is indicated by "*" and $\mathrm{P}<0.001$ by"**".

\section{Discussion}

In the present study, ACR reduced body weight, kidney weight, thickness of cortex and medulla and volume of kidney. Vitamin $\mathrm{C}$ alone increased these parameters compared to the control. Also in ACR+vitamin C group, vitamin C significantly decreased these parameters caused by ACR. ACR is listed by the World Health Organize (WHO) as an eventual human carcinogen (24). According to previous studies, it is supposed that exposure to low doses of ACR could increase the risk of cancer (8). In this study, we demonstrated acute nephrotoxicity supported by histological sections and stereological analysis. The estimated volume obtained from stereological method provided unbiased evidence concerning ACR induced nephrotoxicity and vitamin $\mathrm{C}$ protective effect. Eman $\mathrm{M}$ and colleagues reported that $40 \%$ to $70 \%$ of ACR that attain into blood vessels is excreted via urine within 24 hours in male albino rats (25). This theory may infer that kidney can perform its function to several limits within ACR toxicity. Our research would provide a discernment to verification and collation of hypertrophy, atrophy and formation of tumor in the kidney tissue. Kidneys of rats in ACR group showed inflammatory cells and vascular degenerative changes and necrosis. These findings might have been due to the truth that kidneys are the excretion gateway of ACR and its metabolites. These results were similar to that reported by Mahmood SA et al. (26). WHO reported that in rats, biotransformation of ACR occurs via glutathione expenditure and decarboxylation and at least four urinary metabolites have been found in rats urine (27). Vitamin $\mathrm{C}$ as an antioxidant agent can prevent chain reactions of free radicals or the reactive oxygen species before reaching their renal targets (28). Antioxidant are able to reduce the incidence of fragmentation and subsequent rearrangement induced by pesticides (29) Thus, the results of the present study suggest that vitamin $\mathrm{C}$ improving effects on kidneys are mediated by prevention of free radicals generation and/or free radical cleaning activity. It is concluded by biochemical and pathological alterations that ACR has toxic effect even at low doses. It is suggested for other researchers to investigate the association between dietary ACR intake and renal, bladder and prostate cancer risk.

\section{Conclusion:}

Acrylamide is a nephrotoxic substance and vitamin $\mathrm{C}$ as an antioxidant can protect kidneys from ACR induced tissue damage.

\section{Acknowledgment}

This study was performed in Department of Anatomy and Cell Biology, Shahid Sadoughi University of Medical Sciences and Health Services. The authors would like to thank Mrs. Mirjalili for her technical help. 


\section{Conflict of Interest}

Authors declared no conflict of interest.

\section{References}

1.Khalil F, Aziem B. Effect of dietary acrylamide formed in potato crisps and toasted bread on rats. Egyptian Journal of Natural Toxins. 2005;2:57-70.

2.Lingnert H, Grivas S, Jägerstad M, Skog K, Törnqvist M, Åman P. Acrylamide in food: mechanisms of formation and influencing factors during heating of foods. Scandinavian Journal of Nutrition. 2002;46(4):159-72.

3.Tareke E, Rydberg P, Karlsson P, Eriksson S, Törnqvist M. Analysis of acrylamide, a carcinogen formed in heated foodstuffs. Journal of agricultural and food chemistry. 2002;50(17):4998-5006.

4.Yerlikaya FH, Toker A, Yener Y. Effects of acrylamide treatment on oxidant and antioxidant levels in rats. Kafkas Universitesi Veteriner Fakultesi Dergisi. 2013;19(4):607-12.

5.Kjuus H, Hansteen IL, Ryberg D, Goffeng LO, Øvrebø S, Skaug V. Chromosome aberrations in tunnel workers exposed to acrylamide and $\mathrm{N}$ methylolacrylamide. Scandinavian journal of work, environment \& health. 2005;31(4)300-6.

6.Schettgen T, Weiss T, Drexler H, Angerer J. A first approach to estimate the internal exposure to acrylamide in smoking and non-smoking adults from Germany. International journal of hygiene and environmental health. 2003;206(1):9-14.

7.Rydberg P, Eriksson S, Tareke E, Karlsson P, Ehrenberg L, Törnqvist M. Investigations of factors that influence the acrylamide content of heated foodstuffs. Journal of Agricultural and Food Chemistry. 2003;51(24):7012-8.

8.Fuhr U, Boettcher MI, Kinzig-Schippers M, Weyer A, Jetter A, Lazar A, et al. Toxicokinetics of acrylamide in humans after ingestion of a defined dose in a test meal to improve risk assessment for acrylamide carcinogenicity. Cancer Epidemiology and Prevention Biomarkers. 2006;15(2):266-71.
9.Nixon B, Stanger S, Nixon B, Roman S. Chronic exposure to acrylamide induces DNA damage in male germ cells of mice. Toxicological Sciences. 2012;129(1):135-45.

10.Schettgen $\mathrm{T}$, Kütting $\mathrm{B}$, Hornig $\mathrm{M}$, Beckmann M, Weiss T, Drexler H, et al. Transplacental exposure of neonates to acrylamide-a pilot study. International archives of occupational and environmental health. 2004;77(3):213-6.

11.Hogervorst JG, Schouten LJ, Konings EJ, Goldbohm RA, van den Brandt PA. Dietary acrylamide intake and the risk of renal cell, bladder, and prostate cancer. The American journal of clinical nutrition. 2008;87(5):1428-38.

12.Boettcher MI, Bolt HM, Drexler H, Angerer J. Excretion of mercapturic acids of acrylamide and glycidamide in human urine after single oral administration of deuterium-labelled acrylamide. Archives of toxicology. 2006;80(2):55-61.

13.Maliakel DM, Kagiya TV, Nair CKK. Prevention of cisplatin-induced nephrotoxicity by glucosides of ascorbic acid and $\alpha$-tocopherol. Experimental and Toxicologic Pathology. 2008;60(6):521-7.

14.Kalender S, Kalender Y, Durak D, Ogutcu A, Uzunhisarcikli M, Cevrimli BS, et al. Methyl parathion induced nephrotoxicity in male rats and protective role of vitamins $\mathrm{C}$ and $\mathrm{E}$. Pesticide biochemistry and physiology. 2007;88(2):213-8.

15.Hinchliffe S, Lynch M, Sargent P, Howard C, Velzen Dv. The effect of intrauterine growth retardation on the development of renal nephrons. BJOG: An International Journal of Obstetrics \& Gynaecology. 1992;99(4):296-301.

16.Dezfoolian A, Panahi M, Feizi F. Stereological evaluation of renal glomeruli in offspring of diabetic female rats. Yakhteh Medical Journal. 2009;11(1):17-22.

17.Coulam CH, Bouley DM, Sommer FG. Measurement of renal volumes with contrast-enhanced MRI. Journal Of Magnetic Resonance Imaging. 2002;15(2):174-9. 
18.Howard V, Reed M. Unbiased stereology: three-dimensional measurement in microscopy: Garland Science; 2004.

19.Nyengaard J, Bendtsen T. Glomerular number and size in relation to age, kidney weight, and body surface in normal man. The Anatomical Record. 1992;232(2):194-201.

20.Gage GJ, Kipke DR, Shain W. Whole animal perfusion fixation for rodents. JoVE (Journal of Visualized Experiments). 2012(65):e3564-e.

21.Sterio D. The unbiased estimation of number and sizes of arbitrary particles using the disector. Journal of microscopy. 1984;134(2):127-36.

22.Bertram JF. Analyzing renal glomeruli with the new stereology. International review of cytology. 1995;161:111-72.

23.Skov K, Nyengaard JR, Korsgaard N, Mulvany MJ. Number and size of renal glomeruli in spontaneously hypertensive rats. Journal of hypertension. 1994;12(12):1373-6.

24.Organization WH. The world health report 2002: reducing risks, promoting healthy life: World Health Organization; 2002.
25.Eman M, Amany Y. Some studies on acrylamide intoxication in male albino rats. Egyptain Journal of Comparative Pathology and Clinical Pathology. 2008;21(4):222-45.

26.Mahmood SA, Amin KA, Salih SF. Effect of Acrylamide on Liver and Kidneys in Albino Wistar Rats. Int J Curr Microbiol App Sci. 2015;4(5):434-44.

27.Fennell TR, Friedman MA. Comparison of acrylamide metabolism in humans and rodents. Chemistry and Safety of Acrylamide in food: Springer; 2005;109-16.

28.Adeneye A, Olagunju J. Protective effect of oral Ascorbic Acid (Vitamin C) against Acetaminophen-induced renal injury in rats. African Journal of Biomedical Research. 2009;12(1):55-61.

29.Morsy FA. Protective effect of vitamin c and ginseng on experimental liver and kidney injuries induced by insecticide profenophos in male rats. Egypt J Hosp Med. 2003;10:34-51.

\section{How to Cite This Article:}

Dortaj H, Anvari M, Yadegari M, Hosseini Sharifabad M, Abbasi Sarcheshmeh A. Stereological Survey of the Effect of Vitamin C on Neonatal Rat Kidney Tissue Treated With Acrylamide. Mod Med Lab J. 2018; 1 (2) :42-49 